Pedagogía y Saberes n. ${ }^{\circ} 54$

Universidad Pedagógica Nacional

Facultad de Educación. 2021.pp. 85-96

\title{
Conviene formar al hombre si debe ser tal: la Didáctica Magna de Comenius y el problema de la formación
}

It is Convenient to Train the Man if he Must be Such. The Great Didactic of Comenius and the Formation Issue

homen tem necessidade de ser formado para que se torne homen. A Didáctica Magna de Comenius e o problema da formação

Carlos Jilmar Díaz-Soler*

Para citar este artículo

Díaz-Soler, C. (2021). Conviene formar al hombre si debe ser tal: la didáctica magna de Comenius y el problema de la formación. Pedagogía y Saberes, (54). https://doi.org/10.17227/pys.num54-11803

* Doctor en Educación de la Universidad Estatal de Campinas (Unicamp), Brasil; Magíster en Educación de la Universidad Pedagógica Nacional, Colombia; Psicólogo de la Universidad Nacional de Colombia. Profesor e investigador de la Universidad Distrital Francisco José de Caldas, Colombia.

Correo electrónico: cjdiazs@udistrital.edu.co.

Código Orcid: orcid.org/0000-0003-0944-3046 


\title{
Resumen
}

El artículo, derivado de procesos investigativos, analiza la postura asumida por Comenius sobre la pedagogía, discutiendo aspectos estructurales al vínculo relacional condición humana - escuela. Presenta, para ello, elaboraciones derivadas del programa de investigación “Teoría de 'campo' y procesos de recontextualización” (Universidad Pedagógica Nacional-Universidad Distrital Francisco José de Caldas, Colombia), que trabaja en pos de construir un andamiaje analítico que posibilite la comprensión de fenómenos relacionados con la circulación — recontextualización- de enunciados, materializados en distintas esferas de la praxis y en diversos formatos: trabajos que condujeron a título en pregrado, maestría y doctorado, manuales de metodología de la investigación, textos escolares, artículos periodísticos de divulgación científica, artículos académicos sobre la investigación en educación, noticias sobre la relación entre la educación y la tecnología, por mencionar algunos. Presenta, en pocas palabras, aspectos estructurales de la discusión acerca de la formación, como problema central de la pedagogía.

\section{Palabras clave}

Comenius; Didáctica Magna; pedagogía; escuela; formación; condición humana

\begin{abstract}
This article, derived from a research process, is an analysis of Comenius's viewpoint on pedagogy, particularly about the relationship between the human condition and the school. To accomplish this aim, the article presents points developed along a research program on "Field Theory and Recontextualization Processes" (Universidad Pedagógica Nacional - Universidad Distrital Francisco José de Caldas, Colombia), this program goes on pursuit of a theoretical set to make possible a study on the phenomena related to the circulation and recontextualization of sentences uttered in different contexts and social processes. In summary, this paper presents by means of a few words, some key aspects of a discussion on formation as the central axis of pedagogy.
\end{abstract}

Keywords

Comenius; Didactica Magna; pedagogy; formation; school; human condition

\section{Resumo}

0 artigo analisa a posição assumida por Comenius sobre pedagogia, discutindo aspectos estruturais do vínculo relacional condição humana-escola. Apresenta, para isso, elaborações derivadas do programa de pesquisa “Teoria do 'campo' e processos de recontextualização" (Universidade Pedagógica Nacional-Universidade Distrital Francisco José de Caldas, Colômbia), que visa a construção de um arcabouço analítico, voltado aos fenômenos relacionados à circulação-recontextualização de enunciados, materializados em distintas esferas da práxis e, em diferentes formatos. Apresenta ainda, aspectos estruturais da discussão sobre a formação, como problema central da pedagogia.

\section{Palavras-chave}

Comênio; Didactica Magna; Pedagogia; formação; escola; condição humana 
Hay que procurar que todos aquellos que tienen la misión de formar hombres

hagan vivir a todos conscientes de esta dignidad y excelencia

y dirijan todos sus medios a conseguir el fin de esta sublimidad.

J. A. Comenius (1632)

si el conocimiento es aprendizaje de un saber y el pensamiento es producción-reproducción de un saber, esa diferencia no se refiere a la existencia o inexistencia previa del saber, sino a la forma, a la significación y a las consecuencias de los dos procesos.

[...] la novedad del pensamiento no es un hecho cronológico, es un hecho lógico.

E. Zuleta (1983)

\section{Introducción}

Para 1632, cuando es publicada la Didáctica Magna de Comenius, la discusión sobre la pedagogía ya había iniciado. Las inquietudes relacionadas con la enseñanza, la pregunta por el profesor, las deseables características volitivas y cognitivas en los aprendices o aquellas discusiones sobre el saber - por mencionar algunos aspectos que atañen a la discusión sobre la pedagogía - ya eran asuntos de marcado interés para algunos: Platón (cf. Menón, Banquete...), Clemente de Alejandría (cf. El pedagogo), Juan Luis Vives (cf. Diálogos sobre educación, Las disciplinas, Instrucción de la mujer cristiana), Erasmo de Rótterdam (cf. Educación del príncipe cristiano), por mencionar unos pocos.

En su Didáctica Magna, Comenius (1632) no es la excepción. Dedica especial atención a ciertas discusiones que, en los especialistas contemporáneos, vislumbramos, no despiertan mayor interés. En la actualidad, la discusión sobre la pedagogía centra sus esfuerzos en ciertos aspectos que la circunscriben al ámbito de la técnica o, para otros, a la pretensión de alcanzar resultados deseados, sin que muchas veces se asuma el desafío que conlleva interrogar el estatuto, no solo de aquello que se visualiza como transformable, tampoco se avizoran esfuerzos tendientes a la elaboración de preguntas concernientes a interrogar aquellos instrumentos postulados como indispensables. Las elaboraciones recientes que consideran que lo que fenoménicamente acaece en la escuela es motivo suficiente para el análisis, pierden de vista distinciones necesarias, planos de análisis e instauración de diferentes niveles con los que sería posible desplegar su discusión; mucho menos osan interrogar hasta qué punto las manifestaciones históricas (contingentes) se articulan sobre aspectos estructurales (necesarios).

Al señalar que "conviene formar al hombre si debe ser tal” (1632, vi), Comenius interroga el problema de la pedagogía en uno de sus niveles de análisis: aquel definido por la elusiva pregunta relacionada con la enigmática frase de la conveniencia de la formación. Pero, ¿a qué se refiere con conveniencia?, ¿de qué estatuto habla al postular que "conviene formarlo"?, ¿cómo asume la idea de formación?, ¿cómo socialmente estamos organizados para producir y para "disponer" de los productos que concurrirían a la posibilidad de dicha formación?, ¿qué lugar asignarle a lo necesario y qué papel juega lo contingente en los procesos de formación?

Asumir la pregunta por la formación es interrogar en la Didáctica Manga lo que está en juego, aquello que en su discusión Comenius señala como necesario (en sentido lógico). Ya que toda investigación intenta responder a un problema, nos preguntamos por la manera como él respondió y contestó a su pregunta por la escuela y la enseñanza y, en ella, por la "conveniencia de la formación".

El texto motivo de nuestro análisis presenta, en consecuencia, ciertos valores sobre la condición humana, valores que ordena de acuerdo con una determinada forma que su palabra asume al colocar en el horizonte el problema de la formación. En primer lugar, Comenius establece una necesaria diferenciación que hace de los humanos algo diferenciable de cualquier otra entidad del universo, recorriendo en su elaboración un camino concomitante con su manera de asumir la discusión sobre la condición humana: Comenius investiga, interroga y problematiza qué hace de los humanos algo diferenciable. Análisis que asume al postular que aquello que está en juego es algo más que manejar un vocabulario; trata de comprender, de ubicar en otro nivel el drama al que nos enfrentamos una y otra vez de forma siempre sensible - dada la existencia de la escuela-, no solo en nuestra época, también, en la de Comenius.

Al interrogar la elaboración del saber allí contenido nos preguntamos, además: ¿cuál es el valor de lo reconstruido acerca del pasado en la discusión que nos interesa sobre la pedagogía? Consideramos que no es suficiente con hacer historia: historia de la pedagogía o historias de los pedagogos $y$, decir, por ejemplo, que el libro elaborado por Comenius:

transformó a la pedagogía en la Ciencia de la Educación e hizo que los pedagogos, de simples ayos que eran, se constituyeran en profesionales forjadores de ciudadanos y que colocó, además, al niño en el 
centro del fenómeno educativo, haciendo que todo concurriese a su servicio: maestros, textos, aulas y métodos. (De la Mora, 1922)

Comenius está de lleno planteando su manera de comprender la educación, en su vínculo: con los sujetos, con el saber, es decir, plantea la educación como un escenario distintivo de la situación humana. Ninguna actividad humana se presenta aislada del entramado social.

Si la escuela contribuye a engendrar asuntos específicos de lo humano mediante su accionar es debido a que comporta desde siempre una historicidad fundamental que será necesario precisar. Con este análisis de algunos aspectos de su Didáctica Magna, busco reintroducir no un acento colocado exclusivamente sobre el pasado. Se trata de recuperar la historia a condición de comprender en ella el presente que ha sido vivido allí. Existe una gran distancia entre lo que efectivamente hacemos en la escuela y la elaboración teórica que de ello hacemos... Desfase que nos permitirá salir de la tentación del simple catálogo formal de procedimientos o de categorías conceptuales asumidas bajo la idea de procedimientos que concluyen con agrupamientos simples. Entonces, si de lo que se trata es de generar posibilidades para entender, ¿dónde colocar el acento?

Si fenoménicamente la situación pedagógica se nos presenta como una escena, ello se debe a que le suponemos una estructura que le subyace - posible de inferir merced al acaecer sistemático de ciertos fenómenos- en la que delimitamos ciertas circunstancias. Esta estructura subyacente es la que permite pensar que podemos comprendernos a nosotros mismos y a las instituciones que nos conforman.

En la atmosfera religiosa en la que se sitúa la Didáctica Magna es posible recoger, por un lado, una posibilidad de responder de cierta manera común para la época a los interrogantes fundamentales planteados; pero, por otro lado, en este texto es posible encontrar, también, la materialización de la singularidad con la que Comenius asume su elaboración. Con ello, sería posible pensar en una especificidad de lo humano; es decir, si bien es cierto que con la Didáctica Magna podemos hablar del momento y del contexto en que se halla, podríamos darnos la oportunidad de pensar - gracias precisamente al trabajo de Comenius - que en ella hallamos algo de la singularidad de Comenius frente al problema planteado; marco que, a su vez, da pie para reconocer que su discusión asume la especificidad de lo humano como un efecto: si "conviene formar al hombre si debe ser tal", como nos dice, es porque asume que el hombre no es natural, que se ha desnaturalizado y, con ello, entonces, la educación no es asumida como algo dado, como algo natural..., en palabras de Comenius: "la posibilidad de su formación" asume el horizonte de algo radicalmente distinto de ciertas actividades propias del universo otorgado a los animales ${ }^{1}$.

Constitutivo del horizonte de los sujetos, algo hay en Comenius para que se pregunte por "algo": sus esfuerzos se encaminaron a buscar respuestas a sus inquietudes y, además, a materializarlas en lo que hoy conocemos de ello, gracias, precisamente, a su Didáctica Magna. Al mismo tiempo que constituidos por signos, los humanos son productores de signos; como tales, no pueden reducirse al estado de símbolos o de fichas.

\section{El mundo humano y su especificidad}

Comenius inicia su discusión mostrando que es posible percibir la especificidad del horizonte de lo humano mediante los modos en los cuales nos representamos nuestro último fin, en tanto humanos. Primero, nos dice, somos efecto de una creación: "Dios no mandó secamente al hombre a que existiese, sino que, previa una solemne resolución, le formó con sus propios dedos un cuerpo" (1986, II, 3); cuerpo al que, señala, a su vez le fue inspirada un alma: el segundo elemento que coloca en su discusión. Así, cuerpo + alma configurarían la especificidad de un conjunto relacionado con la diferenciación que estaría elaborando Comenius sobre el hombre y que, con respecto a las demás criaturas, sería su particularidad.

No olvidemos la atmosfera religiosa en la que se sitúa la Didáctica Magna. Un mundo en el cual los hombres son concebidos como el centro de un espacio infinito y son representados en el marco de una construcción a imagen y semejanza de un Dios omnipotente, que designaba sus vicarios en la tierra para que espiritualmente los condujesen como los pastores a sus ovejas, con todas sus autoridades reales cargadas de un poder que emanaba de la gracia de ese Dios (Comenius, 1632, I, 1, 2, 3]. Alma, por lo tanto, en este contexto simboliza aquello que caracterizaría la especificidad humana.

En este marco, asumimos la posibilidad de comprender lo que, a escala de la historia, es posible percibir como contingente: lo social, lo relativo a la cultura, aquello que percibimos que se transforma, que varía; en pocas palabras, lo histórico que busca, en todo caso, elementos que permitan elaborar una

1 Hago uso del término "hombre" en el sentido del conjunto de la humanidad, tal como comprendo que Comenius hace uso de él. 
discusión que incorpore el otro polo constitutivo, también, de esta discusión, aquello que podríamos denominar lo "transhistórico"; dicho de otro modo, lo estructural que convoca y da lugar y hace posibles, a la vez, todas las historias. Analíticamente es posible asumir la discusión a través de la estructura metodológica propuesta por Saussure (1916): lo singular, que atañe a lo propio del sujeto (habla), en el marco de la particularidad de su lengua y de cara a la especificidad (lenguaje), en tanto humanos (universal).

Lejos de poseer las claves de este debate, sí es posible asegurar que no lo resolvemos desde aquellas posturas contemporáneas que podemos agrupar en los siguientes cuatro lugares comunes: 1.buscando una subjetividad artesana de sí misma, correlato de la idea de un sujeto que llega a serlo por unas experiencias singulares, o por la maduración neurológica, o por el despliegue de una libertad esencial; 2. postulando la conducta como resultado de una interacción organismo-medio que se expresaría constantemente a través del par estímulo-respuesta; 3. asumiendo la suposición que el sujeto es fuente y origen del discurso; 4. esgrimiendo la idea común que el yo es autónomo y que puede expresarse recurriendo a la infinita variabilidad que el sistema de la lengua pone a su disposición; Cf: Freud (1929), Lacan (1945, 1949, 1953), Miller (1979), Althusser (1968), Alemán (2006), Braunstein (1980), Pêcheux (1975).

La reflexión sobre la condición humana es un hecho que llama poderosamente la atención de Comenius, máxime cuando, desafiado por el horizonte planteado por la pregunta por la "conveniencia de la formación del hombre", le suma los problemas, las dificultades y los desafíos que encuentra para la materialización de ello. Así, en su disertación, dedica un considerable tiempo a comprender dicha especificidad: en qué radica, qué mecanismo diferenciador hace de los humanos algo diferenciable a cualquier otra entidad sobre la tierra; ya que, señala: "el hombre no existe secamente" y, desde allí, indica algunos desafíos para su enseñanza y, en ello, plantea condiciones de posibilidad de un proceso de formación.

Comenius (1632), al señalarnos que no existimos secamente, nos llama la atención frente a un asunto que merece ser hoy tomado en cuenta para su discusión. Destaca su perenne insatisfacción, como rasgo distintivo de la humanidad. No nos es suficiente todo lo que en esta vida tenemos, lo cual se debe, señala, a su triple vida: "vegetativa, animal e intelectiva o espiritual", con detalle nos explica: la vida vegetativa, "jamás se manifiesta fuera del cuerpo" (Comenius, 1632, II, 4). No asume que la condición humana está determinada por el cuerpo biológico, aunque indica que esa dimensión es un innegable soporte de las otras vidas (animal e intelectiva o espiritual), frente a las cuales establece diferenciación.

Aquella vida que Comenius designa con el nombre de animal, "se dirige a los objetos por las operaciones de los sentidos y movimientos" (1632, II, 10). Comenius diferencia el horizonte propio de los animales que - sabemos hoy- están enmarcados en una escala evolutiva que muestra una compleja articulación entre "saber heredado" (información genética que se despliega automáticamente, como efecto de los estímulos en los comportamientos de cada especie) y "saber adquirido", obtenido gracias a la experiencia que le es posible a cada individuo. Mientras más se asciende en esa gradación, las especies tienen mayor posibilidad de adquirir saber $y$, por lo tanto, una mayor plasticidad los acompaña. Si por dicha escala se desciende, por el contrario, cada especie depende más del "saber heredado" y, en consecuencia, se aprende menos y los comportamientos son más estereotipados. En la lucha por la sobrevivencia, en todos los casos, los animales se sujetan a los estímulos del ambiente que les rodea, filtrados, en todo caso, por ciertos dispositivos genéticamente heredados que condicionan cada una de sus conductas (Darwin, 1859).

Darwin responde también en los marcos de su momento y, gracias a la singularidad de su discusión, nos señala que esa plasticidad, como esa rigidez (propias de toda especie animal, en alguna proporción) no presenta otro objetivo que el de cumplir dos mandatos de la naturaleza: sobrevivir — que se traduce en alimentación y defensa- y perpetuar la especie, mediante la procreación. Sabemos hoy que ninguna acción animal puede ser entendida sin una orientación directa o indirecta a esos fines. Entonces, en este punto de la discusión es lícito preguntarnos por el origen del saber que le suponemos a los animales y los mecanismos mediante los que reaccionan al peligro, por ejemplo; o aquellos mecanismos que le posibilitan la discriminación que les es posible hacer ante aquellos objetos que son alimenticios o frente a otros no alimenticios a su vez: saberes que se despliegan frente a plantas con alguna propiedad astringente, con efectos digestivos... o, específicamente, frente a cuándo y con quién sería posible aparearse.

La respuesta a estos interrogantes, sabemos hoy, integra aspectos relativos tanto al saber genéticamente heredado (instintivo) como al saber adquirido, pero con un marcado determinismo del primero, pues alberga el ineludible mandato genético que desencadena los comportamientos en los animales. Ahora bien, ¿qué es ese "algo" que determina? En 
otras palabras, ¿qué es ese "algo" que se transmite y posibilita los comportamientos para que, como efecto, les sea posible la reproducción y la sobrevivencia?

El saber genético es el mecanismo que posibilita la capacidad de respuesta instintiva que se despliega ante los estímulos externos e internos y requiere para ello de una excitación sensorial proveniente de una fuente perceptiva dependiente de las características constitutivas en cada especie. Cada órgano de los sentidos incide desigualmente - según la especieen el despliegue de comportamientos frente a algo que potencialmente sería peligroso, digno de ser protegido, merecedor de ser ingerido como alimento o, por su parte, adecuado para juntarse sexualmente.

Para los animales es posible entrever que los disparadores de mecanismos de desencadenamiento toman como eje fundamental, por una parte, la referencia a las fuentes perceptivas (lo visual, lo auditivo, los estímulos químicos, lo olfativo...); por otra, cuentan con el apoyo de las imágenes para el desencadenamiento de ciertos comportamientos ${ }^{2}$. En todo caso, para ello disponen - por mandato genético- de un saber del cual no saben: un "saber no sabido", que opera de similar manera para cada animal, en el marco, valga reiterar, de las características de su especie.

Lo señalado nos permite comprender que el mandato genético le dicta a cada individuo la conducta a seguir para sobrevivir y reproducirse, con arreglo a una fidelidad consustancial a cada uno de sus instrumentos perceptivos, propios de cada especie animal. En otras palabras, los procesos disparadores de la conducta en los animales están atados a mecanismos sensoriales, por ende, las respuestas y los desafíos provenientes del ambiente conducen a conductas estereotipadas que como objetivo generan condiciones

2 La imagen que un animal se hace del mundo es absolutamente fragmentaria (no puede percibirlo todo), depende de las limitaciones del dispositivo perceptivo de su especie. La imagen, asimismo, es completamente "objetiva", en relación con lo que le es posible captar a cada animal, según su especie: lo importante no es el mundo en sí, sino la constitución (genética) de ese puntual instrumento mediante el cual le es posible "esa" percepción, cada especie "ve" una realidad diferente. Dos ejemplos: el comportamiento de cada pareja animal está organizado en el marco de la dimensión del pavoneo, algunas aves, al ver la figura en el aire de un depredador, se resguardan; comportamiento que es posible suscitar "en ambientes de experimentación" mediante el sucedáneo papel elaborado por etólogos experimentadores del comportamiento animal. En otra orilla, las elaboraciones provenientes de la psicología de la Gestal plantean dicha discusión sobre la imagen y su papel en la comprensión del funcionamiento del comportamiento animal. Cf. K. Lorenz (1976) para la pregunta por las imágenes en los animales. Por su parte, Lacan (1949), con su trabajo sobre el "Estadio del espejo" arroja luces sobre la función de la imagen (registro imaginario) en la configuración de lo humano. para preservar al individuo (alimentación, defensa y reproducción) y, con ello, a la especie. Cada animal es una cadena de la especie, indiferente a la singularidad.

Así, en un mundo de múltiples estímulos, provenientes de infinitas fuentes, pero filtrado por un dispositivo sensorial — determinado y organizado desde un saber instintivo - que selecciona, jerarquiza y estructura ese mundo no hay escenario posible para renunciar a ser autótrofo o carnívoro; para dudar y, por qué no, decidirse a cambiar de orientación sexual; para preferir el no tener prole; para infringir y no acatar la Ley - que es uno de los modos posibles de estar en el mundo humano- y que no aplica para las abejas, las hormigas o las termitas... por ejemplo, que son gregarias; para agredir o para declarase pacifista y no defenderse; o para oponerse al statu quo y entrar en rebeldía, sublevarse, organizar la insurgencia y, luego, negociar y tramitar un proceso de paz o, por el contrarío, alejarse del mundo, como los eremitas...

A esta posibilidad de estar en el mundo, Comenius la señala como la tercera vida y la designa como intelectiva o espiritual. Esta tercera representación le posibilita a Comenius vislumbrar la radical diferenciación que hace de los humanos algo diferenciable de cualquier otra criatura: "no nos es bastante todo lo que en esta vida tenemos" (1632, II, 2). Nos dice y precisa, más adelante, que la relación del hombre con las cosas que lo rodean es producto de una singular elaboración:

Todas las cosas que hacemos y padecemos en esta vida demuestran que en ella no se consigue nuestro último fin, sino que todas ellas tienden más allá, como nosotros mismos. Cuanto somos, obramos, pensamos, hablamos, ideamos, adquirimos y poseemos no es sino una determinada gradación, en la que, lanzados más y más allá, alcanzamos siempre grados superiores sin que jamás lleguemos al supremo. (Comenius, 1632, II, 2)

Inconformidad perenne, malestar permanente sería característico del hombre, merced a su proceso de desnaturalización:

Una masa informe y bruta: entonces, empieza la delineación del corpúsculo, pero sin sentido ni movimiento. Comienza después a moverse, hasta el momento en que por la fuerza de la naturaleza es expelido al exterior, y poco a poco van entrando en función los ojos, los oídos y los demás sentidos. Con el transcurso del tiempo se manifiesta el sentido interno cuando se da cuenta de que ve, oye y siente. Más tarde ejercita su entendimiento, advirtiendo las diferencias de las cosas; finalmente, la voluntad asume su función de directora aplicándose a ciertos objetos y apartándose de otros. (Comenius, 1632, II, 2) 
La idea de tiempo, luego del nacimiento, sería clave para comprender un proceso que, como efecto, desembocaría en dicha desnaturalización. Dicho de otro modo, si "conviene formar al hombre si debe ser tal", es porque en el mundo del hombre nada es natural, no recurre Comenius a una idea de predisposición innata para explicar cómo se produce lo humano.

Comenius nos indica, en consecuencia, que la particular configuración de los humanos se caracteriza por la falta de límites y su consecuente forma que asume el establecerlos - tanto en el plano individual, como en el social-, ello sería lo propio de la condición humana:

No someterse a ninguna criatura, ni aún a la propia carne, sirviéndose generosamente de todas ellas y no ignorar dónde, cuándo y de qué modo y hasta qué punto se debe prudentemente utilizar cada cosa; dónde, cómo, de qué modo, y hasta dónde hay que condescender con el cuerpo; dónde, cómo, de qué modo, y hasta qué punto se debe servir al prójimo. En una palabra, poder moderar con prudencia los movimientos y las acciones, tanto internas como externas, tanto propias como ajenas. (Comenius, 1632, IV, 4)

Propio de la condición humana, también es, según Comenius:

Que nuestro entendimiento no solamente es ocupado por las cosas próximas, sino también se deja impresionar por las remotas (ya en el tiempo, ya en el espacio) acomete las difíciles, indaga las ocultas, revela las desconocidas e intenta investigar las inescrutables; por lo tanto, es en cierto modo infinito e ilimitado. Si se concediera al hombre una existencia de mil años, durante los cuales, aprendiendo sin cesar siguiera deduciendo una cosa de otra, jamás carecería de objeto a qué dirigirse; tan inmensa es la capacidad de la mente humana que puede compararse a un insondable abismo (...) al entendimiento no se le puede fijar límites. ¿Habremos de negar que tiene capacidad para todo? $(1632, \mathrm{v}, 4)$

Si para los animales esa línea continua que va del nacimiento, del crecimiento a la adultez y, allí, de la reproducción a la muerte, que ineluctablemente se suceden en el marco de los límites que impone su prefiguración genética - mecanismo que organiza el proceso-, asegurado en el marco del despliegue de ciertos dispositivos de desencadenamiento que garantizan su desarrollo, su evolución, para el mundo humano su mecanismo es otro, que opera en contravía de lo natural. Si su especificidad no es en el seno de lo natural, sino que, por el contrario, es una especificidad que se despliega gracias al mismo mundo humano (la cultura), en donde enseñar se hace necesario $a$ causa del abandono de lo natural, es porque, entonces, opera otro mecanismo: el lenguaje. Por ello es fácil encontrar que, en todo periodo histórico y en los distintos grupos humanos, se establecen procesos que, en un primer momento - cada que aparece un recién nacido: uno nuevo- se hagan necesarios procesos de incorporación a la lengua (cultura), para, desplegar luego otros mecanismos, tendientes a la enseñanza.

Así, si los humanos compartimos el "mundo" con los animales, la particularidad de los humanos está relacionada con la necesidad (en sentido lógico) del paso por los signos. Una evidente ilusión, proveniente de cierto modo de funcionamiento del pensamiento - caracterizado bajo el nombre de empirista o sensualista - y aglutinado, también, bajo la discusión sobre la ideología, hace suponer a algunos que el hombre está ante las cosas, que está frente a una esencia que daría la impresión de su inmediatez pura. Hoy sabemos que siempre partimos de una interpretación que hemos llamado simbólica, cultural o ideológica; lo que llamamos la realidad y su manera como la aprehendemos, el pensamiento, está directamente relacionado con nuestro ingreso al mundo humano, con nuestro proceso de desnaturalización, de ahí el origen de nuestros preconceptos, que se constituyen, en principio, en punto de partida para ulteriores procesos.

Lo que diferencia la sociedad animal de la sociedad humana es que esta última no puede fundarse en ningún vínculo objetivable. Debe incorporase la dimensión intersubjetiva para la comprensión de la condición humana. Si los hombres no actúan como los animales, si su horizonte es diferente, es porque intercambian sus conocimientos mediante el lenguaje. La función del lenguaje permite, mediante el símbolo, constituir el grupo. Así, lo simbólico presenta dos vertientes: la vertiente de la palabra y la vertiente del lenguaje. En el horizonte de la palabra es posible comprender las innumerables posibilidades de las identificaciones; asimismo, la palabra opera como función mediadora entre los sujetos. La otra vertiente concierne a lo que puede llamarse el orden simbólico como conjunto diacrítico de elementos discretos, separado. Saussure postula que los elementos toman su valor unos con respecto a los otros. Estos elementos separados están, en cuanto tales, privados de sentido, y forman en su conjugación una estructura articulada, combinatoria y autónoma. Estructura que "está allí, puesto que los elementos solo valen unos en relación con los otros (Miller, 1979, p. 116).

La noción de lenguaje, aplicada al mundo animal, solo tiene curso por abuso de términos. Ha resultado imposible establecer que haya animales que dispongan, así fuera en forma rudimentaria, de un modo de 
expresión que tenga los caracteres y las funciones del lenguaje humano. Las condiciones fundamentales de una comunicación propiamente lingüística faltan en los animales, así sean superiores. Qué caracteriza, en consecuencia, al lenguaje humano: a. No hay lenguaje sin soporte (voz, escritura, gestos, percepción táctil); b. Hablamos a otros que hablan, esa es la realidad humana; c. En el diálogo, la referencia a la experiencia objetiva y la reacción a la manifestación lingüística se trenzan libremente y sin límite: se construyen mensajes, a partir de otro mensaje; d. El contenido del lenguaje humano es ilimitado; e. La sociedad es condición del lenguaje; f. ¿Cómo saber que, frente a lo dicho, se está mintiendo? (Benveniste, 1952).

En tanto sujetos, cada quien no participa de la producción de sí mismo, ya que debió abonarse al mundo simbólico que le preexistía. Somos producidos por otros, humanos a la vez, lo cual instaura una prematuración en el ser humano durante sus primeros años ${ }^{3}$. Así, a los futuros seres hablantes les anteceden seres hablantes que no solo los insertan a la lengua, también están engarzados en una vida social, gracias a que hablan y, en consecuencia, los nuevos hablantes quedan insertos en una lengua y, al mismo tiempo, en unas prácticas. Primero está el símbolo que, a su vez, constituye la estructura del pensamiento humano luego de producirse la encarnación del símbolo en lo vivido imaginario. La intersubjetividad está dada ante todo por la utilización del símbolo y esto desde el inicio. El símbolo solo vale en la medida en que se organiza en un mundo de símbolos (Lacan, 1953). En pocas palabras, en el mundo del símbolo adviene el sujeto, de ahí su singularidad; es decir, viene a un mundo de otros que hablan y esa singularidad es, a su vez, la que hace existir la lengua.

Precisamente es el símbolo el que engendra seres inteligentes. Nada nos impide pensar, en consecuencia, que cada sujeto se realiza en la relación simbólica con el otro en su conjunto y, con ello, vislumbramos la posibilidad de comprender otro de los registros

3 Entre los 6 y los 18 meses hay un rasgo distintivo en la cría de los humanos: un interés lúdico en los infantes se manifiesta, relacionado con su imagen especular, reconoce su imagen, se interesa en ella. Este interés singular del niño da cuenta del grado de prematuración (fisiológicamente inacabado), lo que lo coloca en una situación constitutiva de desamparo. Si el niño goza cuando se reconoce en su forma especular, es porque la completitud de la forma se anticipa respecto a su propio logro: la imagen es indudablemente la suya; pero, al mismo tiempo es la de otro, puesto que él está en déficit respecto a ella. Esta alienación imaginaria, es decir, el hecho de identificarse con la imagen de un otro es constitutiva de un yo en el hombre, y de que el desarrollo en el ser humano está escandido por identificaciones ideales. Es un desarrollo en el que lo imaginario está inscrito, no es puro y simple desarrollo fisiológico (Lacan, 1949; Miller, 1979, p. 111). propio de la condición humana: el imaginario. La regulación de lo imaginario depende de algo que está situado de modo trascendente, es decir, en su potencialidad detonante y posterior articulación singular con el vínculo simbólico proveniente de la particular materialidad de los seres humanos ${ }^{4}$. Así, situamos a través del intercambio de símbolos nuestros diferentes yos: los unos respecto a los otros, lo cual constituye una determinada relación simbólica, enmarcada y dinamizada por el registro imaginario. Con el intercambio simbólico se produce, como efecto, el vínculo entre los seres humanos, es decir, mediante la palabra y, en tanto tal, permite ulteriores identificaciones al sujeto.

El lenguaje solo puede ser concebido como una trama, como una red que se extiende sobre el conjunto de las cosas; significa según las formas de interacción, con lo cual, dado que existe de hecho una discusión acerca de todos los temas de que se trate, planteados con mayor o menor ambigüedad, evidenciados en distintos sistemas simbólicos que ordenan las acciones: religioso, jurídico, científico, político, nos es posible decir, en consecuencia, que no podemos concebir el discurso humano como unitario (géneros discursivos). En palabras de Comenius: "Cualquiera que sea la parte del mundo visible que examinemos nos llevará a la conclusión de que no ha sido creado para otro fin más que el de servir al género humano" (1632, III, 3).

Con lo dicho anteriormente es posible deducir que, si por estructura somos soporte de una lengua, con ello, nos es posible hacernos a cierta manera de referirnos al mundo y discutir su imagen, y, al mismo tiempo, satisfacernos, podemos tomar distancia de lo señalado por Comenius; por intermedio suyo, de todos aquellos que le antecedieron, así como de muchos de los que hoy, también, discuten aspectos relacionados con la pedagogía, al plantear la idea de "tabula rasa", en el sentido de que a la escuela llega cada estudiante como una tablilla sin inscribir; en palabras de Comenius:

Aristóteles comparó el alma humana con una tabla rasa en la que nada hay escrito, pero en la que pueden escribirse muchas cosas. Y de igual modo que en una tabla limpia puede escribirse lo que el escritor quiere o pintarse lo que desee el pintor conocedor

4 Mediante su sostenido trabajo investigativo, que retoma la discusión que Freud inició sobre la condición humana —elaborada a la luz de su práctica clínica- J. Lacan formuló, como uno de los efectos de esa práctica, la elaboración conceptual que le permite postular tres registros fundamentales de la actividad humana: el simbólico, el imaginario y el real (Miller, 1988). 
de su arte, así en el entendimiento humano, puede con igual facilidad fijarlo todo aquel que no ignore el artificio de enseñar. $(1632, \mathrm{v}, 9)$

Así, no reducimos las problemáticas que encontramos -y que contemporáneamente son discutidas en ambientes relacionados con la pedagogía - a ciertas esencias, que atenderían a ideas cuyo horizonte tributaría a algunos determinismos: sociales, culturales o personales existentes; centramos nuestra atención en aspectos de carácter relacional y en aquellos efectos que se suscitan en la regulación pulsional de los sujetos. El mismo Comenius, a propósito de la enseñanza, párrafos más adelante se corrige: “¿De dónde, pues, procede esa prerrogativa de nuestra Mente de existir perfecta por sí, y ante sí sin preparación anterior?" (1632, vi, 4) y, podríamos complementar hoy que, precisamente, ese es el horizonte que asume el desafío para "aquel que no ignore el artificio de enseñar".

\section{La enseñanza y las condiciones de posibilidad para la formación}

Todo lo que se produce en relación con el lenguaje sucede para ser transmitido en el intercambio social. Insistir sobre el carácter social del lenguaje no significa que se otorgue una mayor importancia a su función de comunicación, a sus usos (Bajtín, 1953). Es posible decir, entonces, que el lenguaje es un proceso de transmisión de un mensaje entre al menos dos sujetos hablantes, siendo el uno destinador o emisor y el otro el destinatario o receptor; tanto emisor como receptor son, a su vez, efecto del lenguaje (Kristeva, 1969). En pocas palabras, devinieron sujetos: de acuerdo con Lacan (1953), cada sujeto está configurado de manera singular por el registro simbólico, con arreglo a su registro imaginario y, en todo caso, en el marco de su particular régimen de satisfacción (registro real). He aquí uno de los aspectos del desafío analítico al que nos enfrentamos cuando postulamos que, en el marco del programa de investigación "Teoría de 'campo' y procesos de recontextualización", nos interesa destacar aspectos estructurales a la discusión sobre la especificidad humana, sobre su producción y sobre su devenir y, por ende, sobre las condiciones de posibilidad de su formación, como problema central de la pedagogía. En consecuencia, planteamos una discusión que toma distancia de aquel sujeto que imaginan las "pedagogías modernas": proclive, dócil a los buenos propósitos; idealización que se nos presenta como uno de los obstáculos al que nos enfrentamos hoy, dado que los ideales no son inocuos, pues constituyen uno de los modos con los cuales es posible afrontar la existencia.
La especificidad del mundo humano - en contraste con el modo de operar para el mundo animalestá dada en que "a cada función de la naturaleza le damos un significado cultural". La convención es regla. Para el psicoanálisis el ser humano no es un ser natural, por eso es posible percibir la variabilidad de las culturas y reseñar las transformaciones históricas. Es posible deducir que el esfuerzo de Sigmund Freud permite desentrañar la particularidad de la modalidad de satisfacción del sujeto, que no se realiza como en los animales; el humano, debido a la inmersión en el lenguaje, no sigue las leyes de la naturaleza; él es un ser desnaturalizado, por hablar se ha apartado de sus condiciones naturales y no está sometido a las leyes de la naturaleza.

Humanos y animales viven cronologías diferentes. El animal desde el momento de nacer ya es. Situación incomparable con la de las crías humanas: ellas no son al momento de su nacimiento; podrían llegar a ser si las condiciones de posibilidad para ello lo permiten. Un intricado proceso les espera, uno por uno, para insertarse en el mundo humano. Comprender la radical distinción entre el mundo animal y el mundo humano, implica, en consecuencia, interrogarse por el particular funcionamiento de la estructura misma de su aparato psíquico.

Si Comenius señala que aquello relacionado con lo intelectivo o espiritual sería rasgo distintivo, motivo de inquietud en su tratado, nos indica, además, que hay algo que no puede no estar: la enseñanza:

\footnotetext{
El hombre es a propósito para el trabajo en cuanto a su cuerpo, pero vemos que al nacer solo hay en él una simple aptitud y poco a poco ha de ser enseñado a sentarse, tenerse en pie, andar y mover las manos para servirse de ellas. (1632, vI, 4)

Quede, pues, sentado que a todos los que nacieron hombres les es precisa la enseñanza, porque es necesario que sean hombres, no bestias feroces, no brutos, no troncos inertes. De lo que se deduce que tanto más sobresaldrá cada uno a los demás cuanto más instruido esté sobre ellos. Acabe el sabio este capítulo: el que no aprecia la sabiduría y la disciplina es un mísero; su esperanza (es decir, el conseguir su fin) será vana, sus trabajos infructuosos y sus obras inútiles. (1632, VI, 10)
}

Entonces, si nos caracteriza, en tanto humanos, algo que hace que nuestro mundo sea radicalmente diferente al de los animales podemos, en consecuencia, inferir que para cada uno - uno por uno- posterior a este primer momento de ingreso al lenguaje, la cultura proveerá tanto de escenarios como de horizontes posibles para ocuparse en algo, en el marco de la particularidad de cada contexto. Entonces, gracias a 
la enseñanza sería posible ofrecer unas posibilidades para que el sujeto "pueda ocuparse y, ejercitar de ese modo, su entendimiento y, advertir así, las diferencias de las cosas, para que la voluntad asuma su función de directora y, le sea posible, aplicarse a ciertos objetos y apartarse de otros" (1632, VIII, 5).

Comenius presenta así su postura sobre la necesidad de la escuela y la enseñanza por medio del debate tanto con sus antecesores como con sus coetáneos y, lega su discusión para nosotros: "Nadie puede creer que es un verdadero hombre a no ser que haya aprendido a formar su hombre; es decir que esté apto para todas aquellas cosas que hacen el hombre" (1632, vI, 3).

Dado que la escuela es necesaria, es decir estructural, en otras palabras: no puede no estar, cada periodo histórico la delimita — atendiendo a la particularidad de cada contexto- para que dé forma a sus procesos de enseñanza:

Josefo afirma que después del diluvio el patriarca Sem abrió la primera escuela, que después fue llamada Hebrea. ¿Quién ignora que en Caldea, especialmente en Babilonia, hubo bastantes escuelas en las que se enseñaban las artes entre otras la astronomía? Cuando, posteriormente (en tiempo de Nabucodonosor), Daniel y sus compañeros fueron adiestrados en esta ciencia de los caldeos (Dan., 1. 20), como igualmente en Egipto, donde Moisés fue educado. (Ac., 7. 22). En el pueblo de Israel, por mandato divino, se creaban escuelas, llamadas Sinagogas, donde los levitas enseñaban la ley; éstas duraron hasta Cristo, conocidas por las predicaciones de Él y las de los Apóstoles. De los egipcios, los griegos, y de estos los romanos, tomaron la costumbre de fundar escuelas; y principalmente de los romanos partió la admirable costumbre de abrir escuelas por todo su imperio, especialmente después de propagada la religión de Cristo por el piadoso cuidado de los príncipes y los obispos. La historia nos refiere que Carlomagno, así que sometía gentes paganas, ordenaba a los Obispos y Doctores la creación de templos y escuelas; y siguiendo este ejemplo otros cristianos Emperadores, Reyes, Príncipes y Magistrados de las ciudades, aumentaron de tal modo el número de escuelas que hoy son innumerables. (1632, VIII, 3)

Al intuir Comenius esta radical distinción, precisa la necesidad de la escuela:

En general a todos es necesaria la cultura. Pues si consideramos los diversos estados del hombre hallaremos esto mismo. ¿Quién dudará que es necesaria la disciplina a los estúpidos para corregir su natural estupidez? Pero también los inteligentes necesitan mucho más esta disciplina porque su entendimiento despierto, si no se ocupa en cosas útiles, buscará las inútiles, curiosas o perniciosas [...] Así el espíritu ágil desprovisto de cosas serias se enreda completamente en cosas vanas, curiosas y nocivas y será causa de su muerte. (1632, VI, 7)

Como efecto de ese proceso que devino en su desnaturalización - advino en tanto sujeto- un particular régimen de satisfacción. Al ser necesaria la escuela, los procesos de regulación buscan generar condiciones de posibilidad para la enseñanza, pues nunca están dadas de manera espontánea, dado que la labor que llevaría a la apropiación de específicos asuntos que son propuestos por la escuela, requieren del necesario esfuerzo, dedicación y trabajo, para que algunos se inmiscuyan en ellos. Lo interesante de la discusión, de cara a la pregunta por la especificidad de lo humano, es precisar los mecanismos por los cuales funciona como tal; pues, como esbozamos, si una sociedad sin lenguaje no existe, tampoco puede existir sin procesos de transmisión, como los llevados a cabo con fines de enseñanza.

Por lo tanto, será necesario hacer énfasis en discusiones relacionadas con la producción del sujeto hablante, es decir, que no estamos ante sujetos sometidos a una necesidad. Marco que hace de la escuela un efecto de esta especificidad; en consecuencia, se precisa la importancia de introducir una discusión sobre la disciplina. Planos de análisis que Comenius alude así:

Es asunto en extremo peligroso no imbuir en el hombre los sanos preceptos de la vida desde la misma cuna. Porque el alma del hombre, en cuanto los sentidos exteriores empiezan a ejercer su función, no puede en manera alguna permanecer quieta, no podrá contenerse; de suerte que si no se emplease en cosas útiles se entregaría a otras vanas y aún nocivas (guiándose de los malos ejemplos de nuestro siglo corrompido), Y como ya hemos observado, perder estas costumbres sería, o imposible o, por lo menos, dificilísimo. Por esto el mundo está lleno de enormidades; para resistir a las cuales no bastan ni los magistrados políticos ni los ministros de la iglesia en tanto no se dediquen serios trabajos a cegar los primeros manantiales del mal. (1632, vII, 8)

Comenius está inquieto, nos hace sentir su preocupación de no "procurar que todos aquellos que tienen la misión de formar hombres hagan vivir a todos conscientes de esta dignidad y excelencia". Es decir, de no imbuir, de no inculcar, de no influir "sanos preceptos de la vida": ¿quién dudará que es necesaria la disciplina? Nos dice, dada la existencia de algo que en cada uno bulle (no puede en manera alguna permanecer quieta, no podrá contenerse), señala. 
Imaginar que es posible una espontánea morigeración, sin que introduzcamos desafíos, retos, límites materializados en trabajos propuestos por un otro: lecturas, lecciones, ejercicios, proyectos, tareas... provenientes, a su vez, del Otro (Ley, normas, discusiones sistematizadas...) es comprender poco del estatuto de lo humano y propicia - como es común contemporáneamente escuchar en diversos escenarios dedicados a la enseñanza - asumir, sin mayor reflexión, que los buenos propósitos y las buenas intenciones serán suficientes con los efectos que ya vislumbramos hoy.

Dada la condición humana, la escuela contribuye al proceso de regulación (aparato psíquico) por medio del uso del saber: la regulación es constitutiva de la escuela, en consecuencia. La postura asumida por Comenius frente a la escuela y la enseñanza, podemos decir, es situarlas en un plano de análisis estructural: 1. Todas las épocas necesitan abundantes procesos tendientes a: inhibir, prohibir, sofocar. A escala estructural la escuela es la misma, dada la condición humana: enseñar es necesario. 2. Sofocar aquello que bulle y que produce efectos: inevitable, dada la condición humana.

Como posibilidad para comprender y conceptualizar lo planteado por Comenius, Freud (1913) nos permite elucidar las relaciones posibles con los objetos ofrecidos por la cultura, específicamente aquellos que relacionamos con el saber, ya que, como el mismo Freud señala:

Buena parte de la brega de la humanidad gira en torno de una tarea: hallar un equilibrio acorde a afines, vale decir, dispensador de felicidad, entre esas demandas individuales y las exigencias culturales de la masa; y uno de los problemas que atañen a su destino es saber si mediante determinada configuración cultural ese equilibrio puede alcanzarse o si el conflicto es insalvable. (1929, p. 94)

Ahora bien, si como fue señalado en el epígrafe: "Hay que procurar que todos aquellos que tiene la misión de formar hombres hagan vivir a todos conscientes de esta dignidad y excelencia y dirijan todos sus medios a conseguir el fin de esta sublimidad" (Comenius, 1632), entonces, una discusión que posibilite comprender las condiciones de posibilidad para una formación implicaría asumir el desafío propuesto por Comenius y discutir, entre otros: a. Un maestro con ciertas características, ¿cuáles? b. Precisar ¿qué comprenderíamos por medios que procuren dirigir todos los esfuerzos a conseguir esa dignidad? c. Plantear si, de antemano, es posible prever que serán conseguidos los propósitos, dados los presupuestos esbozados sobre la especificidad de la condición humana. d. Dada la condición humana, ¿qué será nece- sario asumir para "hacer que sea posible hacer vivir a todos esa dignidad"? e. Comprender los criterios de selección que le propinamos al saber, en la tentativa de su transmisión con fines formativos. Elementos constitutivos de una discusión sobre la formación que, como señala Bustamante (2019), están relacionados con: a. una necesaria precisión sobre el concepto de pulsión (resto) ${ }^{5}$, b. una postura sobre cómo comprender a los semejantes (diferenciación y referente), c. un debate sobre la estructura (prerrequisito del sentido) y d. con un reconocimiento sobre el valor de la relación transferencial que da lugar al deseo: el sujeto debe consentir esa imposición en pos de una satisfacción posible ligada a un producto (obra, teorema, desempeño, compresión). Se renuncia a cierta modalidad de satisfacción pulsional imaginando y trabajando para alcanzar otra.

Concitar la posibilidad de formación es algo radicalmente distinto de aquellas actividades propias de los animales, enmarcados en un saber que opera - por mandato genético-automáticamente en ellos. Si es preciso ejercitar el entendimiento, advertir las diferencias de las cosas y la voluntad, asumiendo su función de directora, para aplicarse a ciertos objetos y apartándose de otros, como nos enseña Comenius, es porque está refiriéndose a rasgos distintivos posibles para la condición humana.

\section{Referencias}

Alemán, J. (2006). Notas Antifilosóficas. Ediciones Serie trigrama.

Althusser, L. (1968). La filosofía como arma de la revolución. Siglo XXI.

Bajtín, M. (1953). Estética de la creación verbal. (T. Bubnova, trad.). Siglo Xxi. (2012).

Benveniste, É. (1952). Problemas de lingüística general. México: Siglo XxI. (1971).

Braunstein, N. (1980). Psiquiatría, teoría del sujeto, psicoanálisis (hacia Lacan). Siglo XXI.

Bustamante, G. (2019). La formación como efecto. Editorial Aula de Humanidades.

Comenius, J. A. (1632), Didáctica Magna. Ediciones Akal, Madrid, (1986).

5 La pulsión es un efecto producto del proceso de desnaturalización que da lugar a los humanos. El vínculo entre un viviente y la estructura simbólica por definición es anómalo, es decir, arroja un resto que queda por fuera y es constitutivo de su funcionamiento (Freud, 1915; Miller, 1988). 
Darwin, C. (1859). Textos fundamentales. Paidós Ibérica. (1984).

De La Mora, G. (1922). Prologo. En J. A. Comenio, Didactica Magna. Porrúa. (1982).

Freud, S. (1913). Obras completas, Vol. XII. Amorrortu (1990)

Freud, S. (1915). Obras completas, Vol. XIV. Amorrortu (1990)

Freud, S. (1929). Obras completas, Vol. XXI. Amorrortu (1990).

Kristeva, J. (1969). El lenguaje, ese desconocido. Introducción a la lingüística. Editorial Fundamentos. (1988).

Lacan, J. (1945). El tiempo lógico y el aserto de certidumbre anticipada: un nuevo sofisma. En Escritos I. Siglo XXI (1990).
Lacan, J. (1949). El estadio del espejo como formador de la función del yo tal como se nos revela en la experiencia psicoanalítica. En Escritos I. Siglo XXI (1984).

Lacan, J. (1953). Función y campo de la palabra y del lenguaje en psicoanálisis. En Escritos I. Siglo XxI (1976).

Lacan, J.(1953). De los nombres del padre. Paidós (2007).

Lacan, J. (1953-54). Libro 1 (los escritos técnicos de Freud). Paidós (1988).

Lorenz, K. (1976), Consideraciones sobre las conductas animal y humana. Plaza \& Janes.

Miller, J. (1979). Recorrido de Lacan. Manantial (1990).

Miller, J.-A. (1988). Freud y la teoría de la cultura. En Elucidación de Lacan. Paidós.

Pêcheux, M. (1975). Las verdades evidentes. Lingüística, semántica, filosofía. Ediciones del Centro Cultural de la Cooperación (2016). 